\title{
PARTICIPATION OF MIGRATION OF THE POPULATION IN THE SOCIO ECONOMIC DEVELOPMENT OF THE REGION (ON THE MATERIALS OF THE REPUBLIC OF TATARSTAN)
}

\author{
Niyaz M. Biktimirov ${ }^{1}$ \\ Vladimir A. Rubtzov ${ }^{2}$ \\ Marat R. Mustafin ${ }^{3}$ \\ Mikhail V. Rozhko ${ }^{4}$
}

\begin{abstract}
The article presents the main established. The features of the impact of trends of migration development in Russia. The study reveals the importance of migration processes for demographic development of Russia. The emphasis is placed on the migration exchange of the Republic of Tatarstan with foreign countries. The main trends, associated with a decrease in the number of immigrants from almost all CIS countries, except Ukraine, are defined. Particular attention in the article is paid to the migration processes, and the importance of labor migration for the Republic of Tatarstan. Gender studies in modern migratory movements are presented. The main reasons why foreign migrants, working in Tatarstan, on national security are disclosed.The issues, related to the influence of foreign labor migrants on the ethnic composition of the Republic of Tatarstan were defined. The State Program of the Republic of Tatarstan, promoting the sustainable social, economic and demographic development of the republic, due to the voluntary resettlement of compatriots living abroad, was analyzed.The data of the Federal Service - Territorial Body of Federal State Statistics Service in the Republic of Tatarstan, are widely used in work.
\end{abstract} Tatarstan is an attractive territory for migrants not only from Russian regions, but also from other countries, are

Keywords: migration, migration processes, migration gain, national

\footnotetext{
${ }^{1}$ Kazan Federal University. e-mail: Niyaz825@mail.ru. Tel.: 89600509417

${ }^{2}$ Kazan Federal University. e-mail: Niyaz825@ mail.ru. Tel.: 89600509417

${ }^{3}$ Kazan Federal University. e-mail: Niyaz825@mail.ru. Tel.: 89600509417

${ }^{4}$ Kazan Federal University. e-mail: Niyaz825@mail.ru. Tel.: 89600509417
} 
security, labor migration, migration policy.

\section{Results and discussion}

The analysts from the National

\section{Introduction}

Migration processes in the socio-economic and demographic development of Russia are of paramount importance. Among the huge number of both positive and negative consequences of migration for modern Russia, it is necessary to emphasize the compensating role of the natural population decline, which at the certain stages of country's development since the 90 s, covered up to $70 \%$ of population losses, due to the low birth rates and high mortality rates.

According to statistics, over the past two decades, the migration gain in Russia is 7 million people. According to the forecast, by 2025 , the number of migrants in the population of the Russian Federation may amount to more than 10 million people.

\section{Methods}

The methods of analysis and synthesis of scientific literature, published in Russia and abroad, were used in the work. General approaches were applied during the study. 
The specialists from the Higher

School of Economics believe that the data on migration for this period are difficult to compare, due to the multiply changes in their accounting. Also among the current trends, family migration (parents with children) can be distinguished [2].

It should be noted, that in terms of the number of illegal migrants among the world countries, Russia is the second after the United States.

There are studies, aimed at identifying the countries, leading under the criterion of illegal migrants. These countries are the following: Georgia, Moldova, Azerbaijan and Uzbekistan. It turned out, that illegal workers from Belarus occurred only in exceptional cases [3].

There are significant gender differences in modern migration movements. For example, one of five women is divorced or widowed. Individual studies show that female migrants are older and more educated than male [4].

In terms of attractiveness to foreign migrants, the regions of Russia are very much different. Being one of the leading regions for sustainable social and economic development, the Republic of Tatarstan forms a positive migration balance with the vast majority of Russian regions [5].

According to the data of Territorial body of Federal state statistics service in the Republic of Tatarstan for 2016, the immigrants provided an increase in the population of the republic by 3502 people.

From the 50s of the XX century to the present day, migration processes play an important role in the demographic development of population of the Republic of Tatarstan.

According to statistical data for 2016 , it turned out that the number of migrants, resettling within the republic, amounted to 53.8 thousand people [6]. Already in 2017, 266.3 thousand foreign citizens were registered at place of stay in Tatarstan (for comparison: 241 thousand people in 2016).

Geographical spread of foreign citizens, arriving in the Republic of Tatarstan, remains practically unchanged. As before, the largest share of migrants comes from Uzbekistan, Ukraine, Azerbaijan, Tajikistan, Kyrgyzstan, as well as from non-CIS countries (Turkey, China and Germany). 
Peoples from these countries are labor migrants. This was stated by $39 \%$ of the total number of foreign citizens, arriving in the republic for the first time.

According to the data of Territorial body of Federal state statistics service in the Republic of Tatarstan for 2012-2016, only the population growth ensured the balance of migration. If in 2012, the migration gain in the Republic of Tatarstan amounted to 9786 people, then in 2016, it was 5880 people. This indicates a decrease in the value of indicator. The decrease is typical for both urban and rural population. Moreover, it is based on the migrants from other countries. On the contrary, migration gain, obtained due to the exchange with the regions of the Russian Federation, tends to increase.

As for Russia as a whole, and for Tatarstan, a significant decrease in the influx of migrants from Uzbekistan is characteristic. If we compare the number of immigrants from Uzbekistan and Ukraine, in 2012 the number of people from Uzbekistan was 11 times higher (Uzbekistan - 3002 people, Ukraine 272 people); in 2016, the number of immigrants from Ukraine was 2.5 times higher than from Uzbekistan
(Uzbekistan - 335 people, Ukraine - 851 people). Migrational exchange of Tatarstan with Ukraine has always been positive. During 2012-2016 it increased threefold. In recent years, the highest migration gain was in 2015 and amounted to 933 people.

In general, there is a decrease in the number of immigrants from almost all CIS countries, except Ukraine. Despite this, a positive migration gain is maintained. Baltic countries are the exception; the indicator of migration balance with them in some years was even minus, but not more (-1 people).

The issues of attraction of labor resources from other countries are important for almost all regions of our country. The Republic of Tatarstan is no exception in this process. The point is that the implementation of grandiose projects in the field of industry, agriculture, transport and culture largely depends on the availability of a sufficient number of labor resources, in the total volume of which the migrants have recently taken significant place. At the same time, the attraction of a large number of workers from abroad can significantly aggravate the problems of unemployment for the local population, 
and ultimately become a threat to the national security of the Russian Federation [7].

In Russia, the struggle within the Muslim community, associated with the definition of Islam, continues [8;9].

Migration in the modern conditions is highly dependent on living standards. In particular, this may be due to the crime situation in various regions of the Russian Federation. In many respects, the presence of a long state border of Russia with other countries and, primarily with the countries of Central Asia, contributes to this. The point is that here are the main channels of penetration into our country of weapons, drugs, low-quality consumer goods, etc. In addition, the crime rate is significantly increased due to the arrival of a large number of people from Afghanistan, Kyrgyzstan, Uzbekistan and other countries [10].

The study of migration process with other countries in the context of "city" and "village" allows to see the similar dynamics in migration gain. In the urban areas of the Republic of Tatarstan it was 3.9 times higher, than in the rural areas. For example, according to the statistics for 2010 , the difference was only 2.1 times. According to the data of Tatarstanstat for 2016, the highest migration growth in the cities was provided by the people from Ukraine (744 people), and in the villages - by the people from Tajikistan (142 people).

At the same time, it is necessary to note, that the migration exchange with the non-CIS countries and the Baltic States is also declining. Since 2014, the migration gain of the population has been replaced by the migration loss (-136 people), in 2015 (-114 people), in 2016 (- 47 people).

In January-November 2017, due to the migration, there was an increase in the total population in the Republic of Tatarstan by 4.4 thousand. This is 1,500 people less compared to 2016 (it should be noted, that the same periods of different years are taken as the basis). It is due to a decrease in the number of immigrants from other regions of the Russian Federation, and an increase in the number of emigrants. The number of people, resettling within the Republic of Tatarstan, amounted to 51.4 thousand people. This is $4.6 \%$ less, compared to the same period in 2016 [11]. 


\section{Summary}

Thus, in current times, the labor migration plays a pivotal role in the socio-economic development of the territory, and is actively used as an effective tool for the regulation of modern labor market.

In the future, the number of citizens, belonging to the category of unemployed, calculated according to the methodology of the International Labor Organization, is likely to be continuously reduced. The decline in unemployment can fundamentally affect the change in demographic structure, accompanied by a significant reduction in youth, who are at risk of unemployment most of all [12].

In the Republic of Tatarstan, the opponents of immigration do not exclude the ethnic conflicts as a result of social tension. This can also be caused by migration processes, because, as evidenced by the identified cases, there may be the proponents of "nontraditional" Islam.

\section{Conclusions}

The Republic of Tatarstan has always placed special emphasis on the migration policy.
For example, a special project

"Tatarstan is the center of population attraction in the Volga Region" has been developed. Its aim is to ensure the influx of qualified specialists into the region. It may be possible if the potential migrants from other regions of Russia show interest in Tatarstan.

In 2014, 3819 foreign citizens obtained temporary residence permits; that is $38 \%$ higher than in 2013, and 819 more than planned.

The State program of the Republic of Tatarstan was developed not only to solve the socio-economic problems, but also to improve the demographic situation in the region. To achieve the main goal, the possibilities of voluntary resettlement of compatriots, living in other countries, are considered.

According to this State program, the following tasks are the most relevant for the Republic of Tatarstan:

- firstly, the need to maintain demographic growth, despite of the unfavorable periods of "demographic waves";

- secondly, mitigation of population ageing and rapid increase in the load on the working-age population; 
- thirdly, maintaining the positions of the project "Tatarstan is the center of attraction of population migration" [12].

\section{Acknowledgements}

The work is performed according to the Russian Government Program of Competitive Growth of Kazan Federal University.

\section{Bibliography}

Bautista H., Tregubova Y., Zinovyeva A.A. Evolvement of ecotourism to build development strategies in the VolgaViatka district // Orbis. - 2018. - № 14 / International Special. - Pp. 205-214.

Russian Population in 2015: TwentyThird Annual Demographic Report / Executive editor S.V. Zakharov; National Research University "Higher School of Economics". - M.: Publishing House of the Higher School of Economics, 2017. - 360 p.

Gimpelson V.E., Zudina A.A. Informal Workers in the Russian Economy: Who Are They and How Many? // National Research University "Higher School of
Economics". - M.: Publishing House of the Higher School of Economics, 2011.

Mukomel V.I. Migrants in the Russian labor market: employment, mobility, intensity and payment // Statistics and Economics. Vol. 14, No.6, 2017.

Shabalina, S.A., Rubtzov, V.A., Pratchenko, O.V. Differentiation of the Territory of Tatarstan Republic into Zones, due to their Significance for Domestic and National and International Tourism. Mediterranean Journal of Social Sciences- 2014.

Resolution of the Cabinet of Ministers of the Republic of Tatarstan, dated October 30, 2007, No. 821. On Approval of the State Program of the Republic of Tatarstan "The Provision of Assistance to Voluntary Resettlement to the Republic of Tatarstan of Compatriots, Living Abroad, for 2017-2018", and Amending the List of State Programs of the Republic of Tatarstan.

Eidelman, B.M., Fakhrutdinova, L.R., Galimov, S.S. Applying of the territorial marketing technologies in organizations of socio-culture service and tourism. 
International Business Management. Vol. 10, Issue 23, pp. 5568 - 5571. 2016.

Gabdrakhmanov N.K, Biktimirov N.M, Rozhko M.V, Problems of Development of Halal Tourism in Russia // Journal of Organizational Culture, Communications and Conflict. - 2016. Vol.20, Is. Special Issue 2. - Pp. 88-93.

Gabdrakhmanov N.K, Biktimirov N.M, Rozhko M.V, Mardanshina R.M. Features of Islamic Tourism // Academy of Marketing Studies Journal. - 2016. Vol.20, Is. Special Issue. - Pp. 45-50.

Biktimirov, N., Gabdrakhmanov, N., Rubtsov, V., Mustaphin, M., Arzhantseva, N. Peculiar Features of the Tatar People Migration on the Territory of Tatarstan // Mediterranean Journal of Social Sciences, Volume 5, Issue 24, November 1, 2014, pp.267-271.

Migration gain, loss (-) of the population in the Republic of Tatarstan [Electronic resource]. Available at: http://tatstat.gks.ru/wps/wcm/connect/ro sstat_ts/tatstat/resources/22ba15004e76 c82a82eeb7cc5af035be/ (Date of access:

May 26, 2019).

Resolution of the Cabinet of Ministers of the Republic of Tatarstan, dated October 30, 2007, No. 821. On Approval of the State Program of the Republic of Tatarstan "The Provision of Assistance to Voluntary Resettlement to the Republic of Tatarstan of Compatriots, Living Abroad, for 2017-2018", and Amending the List of State Programs of the Republic of Tatarstan. [Electronic resource]. Available at: https://docviewer.yandex.ru (Date of access: June 24, 2019) 